\title{
On the Images and Tragedies of Three Females in The Plain of White Deer
}

\author{
Jun Wang ${ }^{1}$ \\ ${ }^{1}$ School of Foreign Languages, Xi' an Aeronautical University, Xi'an, China \\ Correspondence: Jun Wang, Room 301, Building 12, Dongtai Chengshi Zhiguang, Biandong Street, Xi'an City, \\ Shaanxi Province, China. E-mail: 278310057@qq.com
}

Received: February 12, 2020 Accepted: April 1, 2020 Online Published: April 12, 2020

doi:10.5539/ells.v10n2p35 URL: https://doi.org/10.5539/ells.v10n2p35

\begin{abstract}
The Plain of White Deer, known as a "secret history of China", unfolds the historical changes of Weihe Plain in more than half of the last century. Based on the fates of different females, the novel tries to disclose the cruel oppression of the feudal clan system on women and the low status of women as a child-bearing tool in the patriarchal society. This paper will analyze the miserable fates of the three main females Tian Xiao'e, Lu Lengshi and Bai Ling in the novel and also the reasons for their tragic fates.
\end{abstract}

Keywords: The Plain of White Deer, female image, feudal ethics, tragic fate, marriage

\section{Introduction}

The famous novel The Plain of White Deer (Bai Lu Yuan in Chinese), written by Chen Zhongshi, reveals the social features of Weihe Plain, a rural region in Shaanxi Province of China, from the late Qing Dynasty to the middle of the twentieth century. The novel focuses on the conflicts between Bai family and Lu family, two dominant families at the village Bai Lu Yuan, and creates a great many classical characters. Among those characters, female ones are considered the "soul" of the whole story while male ones are regarded as the "skeleton" of the novel. This paper will place the emphasis on analyzing the three female images Tian Xiao'e, Lu Lengshi, Bai Ling and their tragic fates.

These three women had different life experiences, but they shared the same fate. Tian Xiao'e, representing the rebellious female image, received material enjoyment from her ex-husband Guo Jvren, but who only treated her as a tool to release his sex desire. On the contrary, she obtained personal freedom and happiness from Heiwa, the person she loved so much, but lost the comfortable living conditions and finally died of feudal ethics; $\mathrm{Lu}$ Lengshi, representing the obedient female image, ended up with becoming a lunatic under the double pressures of internal desire and external ethics; Bai Ling, representing the independent female image who had received modern education, dreamed of marriage freedom and fought hard for the liberation of all oppressed people in China. In spite of her devotion to the revolutionary cause, she still could not escape from the tragic fate of death.

The female tragedies displayed in this novel were not individual cases in the feudal society, but the common fate of women in the context of the small-scale peasant economy. Chen Zhongshi's description of women in the old society was not only to expose the dark realities, but also to encourage Chinese women to be independent and get rid of the fate as men's slaves and fertility tools in the patriarchal society. They were expected to acquire new knowledge and culture, and develop independent and sound personalities so as to become self-confident females, just as Bai Ling.

\section{Tragic Fates of the Three Females in the Novel}

\subsection{Tian Xiao'e: Fighting for Happiness Through Sex}

Tian Xiao'e was born in a scholar's family. Driven by the idea of a perfect match, her father married Tian Xiao'e to Guo Jvren, a successful candidate in the imperial examinations at the provincial level. There was no love between Guo Jvren and Tian Xiao'e, and Guo Jvren's behavior towards Tian Xiao'e was immoral. She was just a sex tool for Guo Jvren. Tian Xiao'e refused to accept the miserable fate and tried hard to cope with Guo Jvren's inhuman treatment. The encounter with Heiwa gave her hope for new life, so she ran away with Heiwa. However, the marriage without the consents of their parents was not blessed by the family of Heiwa. Worse still, she was regarded as a witch and slut, not allowed to enter the ancestral hall of Lu Family. Expelled from home by Lu San, 
Heiwa's father, she lived in a deserted cave outside the village Bai Lu Yuan, and suffered all unfair treatments silently. All of these did not affect her pursuit of a stable and ordinary life. In her inner heart, she still hoped that her marriage would be understood and recognized by the family of her husband Heiwa and other villagers someday. However, this was just her illusion about the feudalistic village.

After the failure of the peasants' association, Heiwa took flight, leaving Tian Xiao'e to confront public opinions from villagers of Bai Lu Yuan alone. The tough life forced her to have an affair with Lu Zilin, a coward but crafty character in the novel. To take revenge on Bai Jiaxuan, the clan leader of Bai Lu Yuan, Lu Zilin intimidated Tian Xiao'e to seduce Bai Xiaowen, the eldest son of Bai Jiaxuan. For the disillusionment about marriage and inability to revolt the discrimination from villagers, she could do nothing but resort to sex to survive in the village, which led to her final death. Her scandals were spread quickly among villagers, making Bai Jiaxuan, Lu Zilin, and Lu San humiliated. Unable to bear the shame, Lu San murdered his daughter-in-law in a rage.

Tian Xiao'e lost her young life for the improper resistance against the marriage arranged by her parents, the rejection from villagers of Bai $\mathrm{Lu}$ Yuan, and the seduction of Lu Zilin. Tian Xiao'e was faced with an unbreakable iron net, as Mary Wollstonecraft said: "When society does not give a woman a little living space and a little dignity, how can she stick to her bottom line?" (Xu, 2011). At the village dominated by the feudal clan system, what Tian Xiao'e could do was just the desperate resistance against the oppression through sex. In order to relieve a plague occurring after her death, the clan leader organized villagers to build a pagoda to suppress the disaster that they thought was brought about by the unclean woman.

Generally speaking, "The ideal of Tian Xiao'e was just to be a perfectly justifiable wife of a peasant, but the little hope was ruled out by the conservative clan leader Bai Jiaxuan with the excuse of feudal ethical codes" (Lei, 1993). In the patriarchal society, women were in a passive position, and their resistance was always in vain. In her short life, Tian Xiao'e could not escape from the cage of marriage tragedy in spite of twists and turns during her pursuit of happiness. For the deep-rooted patriarchal ideology, it was difficult to change the clan rules and regulations. All villagers were trapped in the small world of Bai Lu Yuan with the ancestral hall as the ultimate goal, and they were educated just to receive the arrangement of fate passively. Any person who refused to accept the feudal ethics would be considered divergent by the villagers and should be expelled from the patriarchal clan. The mainstream value of the village happened to constitute the social background of Tian Xiao'e's tragic life.

\subsection{Lu Lengshi: Longing for Love in Loneliness}

Lu Lengshi was depicted as an abandoned woman in the novel. As a victim of the feudal traditional marriage, she struggled to survive in the conflict between traditional culture and inner desire. She had an arranged marriage, but with a person having received modern education. Her husband Lu Zhaopeng, deeply affected by modern civilization, longed for the freedom of marriage, and was unwilling to accept the marriage arranged by his parents. However, due to the strong force of feudal tradition, he could not divorce Lu Lengshi but choose to leave home. His evasion made his marriage exist in name only, and his wife became a grass widow, which finally resulted in the tragic life of Lu Lengshi.

$\mathrm{Lu}$ Lengshi only spent one night with her husband, and was then left at home alone. Feudal ethics and morality required her to comply with the old rules at the village until she died. She did not have the right to make active choices but accept the arrangement of fate passively, behaving like a good daughter-in-law, and being filial to her father-in-law and mother-in-law. She lived a lonely life, with her physiological need not met, which eventually led to her psychological distortion. Although compelling herself to abide by feudal ethics, Lu Lengshi could not control her physical need. She often met her husband in dreams so as to live through the lonely days and nights.

After her drunken father-in-law Lu Zilin rubbed her breasts, Lu Lengshi started to have a vague feeling about sex, and her desire and fantasy for sex intensified her inner conflict between reason and desire. She put wheat grass in Lu Zilin's bowl to revenge him, which showed her wish to stick to chastity as a traditional woman; on the other hand, she actively courted her father-in-law, revealing her wish to be caressed. In the world of life, she clearly knew that her ideas were shameful and immoral, but in the world of desire, she also yearned for the caress of men, even the caress from her father-in-law. The chastity education she received from the feudal society made her deny the desire for sex, but her body betrayed herself constantly. She desired to have her physiological need satisfied, and also tried to be a woman who abided by female virtues. When either of the two colliding wishes could not come true, she gradually became unable to bear the pressure, and went insane.

Villagers at Bai Lu Yuan did not show any sympathy for the madness of Lu Lengshi, but even despised her. Mr. Leng, her father, did not care about his daughter's misfortune and suffering. For the sake of the two families' reputation, he prescribed a dosage of drug for her daughter, who then became dumb and finally disappeared from 
the village. Still, no one sympathized with her even after her death, and only a heavy snow seemed trying to cover up the tragedy. Chen Zhongshi attempted to reveal the evilness of feudal ethics and criticize the traditional morality with the short, miserable life of Lu Lengshi. She died so tragically and innocently, but no one could tell who killed her, her husband, her father-in-law, or her father? As a matter of fact, it was the invisible feudal ethics and traditional culture that resulted in her death.

According to Maslow's Hierarchy of Need theory, sexual instinct belongs to the most primitive and lowest need, and it is also the first need that people must meet (Maslow, 1987). Lu Lengshi yearned for sex, but also wanted to be a chaste woman. She struggled between desire and reason, but at the same time, she was abandoned by both of them. She could neither meet her physiological need nor be a woman who stuck to female virtues. She made a cage for herself and imprisoned herself in it, which eventually led to a tragic fate.

\subsection{Bai Ling: Seeking for Freedom Through Education}

Compared with other female images in The Plain of White Deer, Bai Ling was the luckiest woman in the feudal society, and this luckiness mainly came from her personal experience and living environment. Born in a rich family and loved by her parents, she had received good education in her childhood. After growing up, she learned new culture and new ideas in a new-style school in the city, and participated in the training of democratic revolution. Such experience and family background made her avoid suffering the plight and pain from which most of women at that time could not escape.

Due to the great historical span of the novel, Bai Ling had gained the growth of self-consciousness and mature external image in this turbulent era. She was the only female in this novel who was not mentally devoured by the feudal ethics. She not only cast away the traditional thought and acquired the free marriage, but also actively contributed to the society in the national liberation movement, displaying a legendary and romantic female image to readers.

Education made Bai Ling different from other women in the feudal society. Because of education, she had the courage to find her true love, breaking through the feudal constraints and pursuing equal and free love. The love between her and Lu Zhaohai was full of happiness. They appreciated each other, and respected each other's life value and independent personality. However, their love was based on their common aspiration, namely liberating the old China through revolution.

Bai Ling and Lu Zhaohai finally broke up due to different political views, which, on the contrary, reflected that she possessed the characteristics of modern educated women: strength, independence, and courage. Such critical spirit and rebellious consciousness had a direct impact on the women who pursued freedom and liberation in real life. For the need of revolution, Bai Ling and Lu Zhaopeng disguised as a couple, and eventually fell in love with each other after sharing weal and woe together.

However, as a woman in the feudal society, Bai Ling still could not completely evade the influence of the traditional ethics. She disobeyed her parents' orders, refused to accept the arranged marriage, and courageously pursued free marriage, which was a great shame to her father Bai Jiaxuan. Bai Ling paid the price of being discarded by her family for the real freedom in marriage. In the novel, Bai Ling was the only new woman with knowledge, culture and modern education. She expected the early liberation of China, constantly took part in political activities, had the great national aspiration, and dedicated herself to the revolution.

Bai Ling was lucky to be raised in a rich family, but she still could not escape from the fate of dying young. "A white deer ran to me from afar, gazing at me, with tear in her eyes. I could clearly see that she was crying. Several seconds later, she turned around to the west and disappeared quickly. At the moment of disappearing, she changed into Bai Ling, and even called me 'Dad', with the voice full of grievance" (Chen, 1997). Having such a dream at the night of Bai Ling's death, Bai Jiaxuan realized that he had lost her beloved daughter forever. For most of women at Bai Lu Yuan, Bai Ling was doubtlessly fortunate since she received modern education, dared to pursue her true love, and bravely went for what she believed in. She was the only positive image of females depicted by Chen Zhongshi in the novel; on the other hand, she was also unfortunate for the reasons of history. She shed her blood in the era of revolution, and made the great contribution to social progress, but her fate ended in tragedy. White deer was not only the incarnation of Bai Ling, but also the incarnation of thousands of new women in the era losing their lives for a better future.

\section{Reasons for the Tragic Fate of Females in the Novel}

\subsection{Persecution of the Patriarchal Clan System}

The patriarchal clan system had existed in China for thousands of years. Based on the patriarchal lineage, and relying on the production mode of farming, it was the foundation of the traditional social political system and an 
important factor to stabilize the society. At Bai Lu Yuan, the patriarch, village convention and ancestral hall symbolized the clan system and were the unshakable authority in the villagers' mind. There is no doubt that the patriarchal clan system maintained social stability by suppressing people's desire, so the patriarch prohibited the appearance of all factors with rebellious nature and unconducive to the maintenance of clan ethics. Parents in the clan society had the right to decide on their children's marriage. They believed that the young men and women in the clan should abide by "the orders of their parents and the words of matchmakers". Tian Xiao'e was regarded as a "bitch" and was excluded from the ancestral hall; Lu Zilin forced Lu Zhaopeng to marry Lu Lengshi with three slaps on his face; and Bai Jiaxuan severed the relationship with his daughter after Bai Ling refused to accept the arranged marriage. The patriarchal clan system emphasized the idea of preserving the natural principles and eliminating human desires so as to guarantee the central position of clan ethics.

\subsection{Oppression of the Traditional Chastity View on Women}

In feudal society, women's chastity was deemed more important than everything else. Influenced by the traditional thought of "being loyal to their husbands until their deaths", women had to suppress their normal psychological and physiological desires. They were not considered the real "human", but the tool to maintain feudal ethics and traditional virtues. Women were expected to serve men, depend on men to survive, and give birth to pure descendants for their clans. Tian Xiao'e was required by her parents to marry Guo Jvren, who was nearly sixty years old, and suffered various humiliations. She chose to resist the tradition and actively pursued her love and desire. But in the patriarchal society, Tian Xiao'e's instinctive pursuit of love was destructive to social ethics and chastity, so she was regarded as a "slut" and was forbidden to enter the ancestral hall symbolizing the authority of the clan. Bound by the traditional idea, and daring not to break the taboos, Lu Lengshi could do nothing but bear the pain of psychological and physical conflict on her own, and collapsed in the extreme mental distortion at last.

\subsection{Child-Bearing Tool in the Traditional View}

Under the background of the small-scale peasant economy in the feudal society, women, for their weak labor ability, could only realize their life value through childbirth. The first criterion to judge a married woman was not whether she was virtuous and thrifty, but how much she contributed to the continuation of the family. Bai Jiaxuan married seven women in his whole life, and the first six died unfortunately for various reasons, but the villagers didn't remember them at all, as if they were just old torn clothes. The six wives had not given birth to any child for Bai Jiaxuan, and in the traditional view, there were three forms of unfilial conducts, of which the worst was to have no descendants. In order to continue the family line, his mother compelled him to get married just after his father passed away, which was against the conventions. In her mother's mind, a woman was just the paper for pasting windows, which could be replaced easily after torn. She was even ready to spend all the family wealth on her son's marriage as long as the next one could bear children for his son.

\section{Conclusion}

"The essence of tragedy lies in the conflict between human's natural desire and moral responsibility or insurmountable obstacles" (Belinskiy, 1962). The three kinds of women mentioned by the author, with their personal strength, fought against the patriarchal clan ethics that had existed for thousands of years, and they were doomed to fail and lead miserable lives. However, some of them were reluctant to yield to their fate, and struggled for their happiness bravely, revealing the brilliance of their indomitable spirit. The tragic fates of women portrayed by Chen Zhongshi in The Plain of White Deer showed his deep reflection on women's liberation. How to realize women's real freedom in human nature and spirit is a very realistic problem. Women are the indispensable part of human being, and their social status can accurately reflect the degree of social progress. However, women could only serve as accessories of family in the patriarchal society. They were even deemed to cause troubles in ancient times, without real freedom, independent personality, and even basic dignity. The tragic lives of women depicted in The Plain of White Deer revealed the suffering of women in the feudal society at that time, and also Chen Zhongshi's concern and sympathy for women's fate.

\section{References}

Belinskiy, W. E. (1962). Dramatic Poems (p. 138). Beijing: People's Literature Publishing House.

Chen, Z. S. (1997). The Plain of White Deer (p. 267). Beijing: China Renmin University Press.

Lei, D. (1993). Spirit in Ruins - On The Plain of White Deer. Literary Review, 6, 105-118.

Maslow, A. H. (1987). People's Potential and Value (p. 158). Beijing: Huaxia Publishing House.

Xu, G. Z. (2011). Viewing Women's Liberation of Self-consciousness from The Plain of White Deer. Journal of 
Bijie University, 29(12), 110-115.

\section{Copyrights}

Copyright for this article is retained by the author, with first publication rights granted to the journal.

This is an open-access article distributed under the terms and conditions of the Creative Commons Attribution license (http://creativecommons.org/licenses/by/4.0/). 